\title{
Heat flow, heat capacity and thermal resistance of localized surfaces of the human body using a new calorimetric sensor
}

\author{
Pedro Jesús Rodríguez de Rivera ${ }^{1,2} \cdot$ Miriam Rodríguez de Rivera $^{1} \cdot$ Fabiola Socorro ${ }^{1} \cdot$ Gustavo Marrero Callicó $^{2}$. \\ Jose A. L. Calbet ${ }^{3,4} \cdot$ Manuel Rodríguez de Rivera' $^{1}$
}

Received: 13 January 2021 / Accepted: 31 August 2021 / Published online: 18 September 2021

(c) The Author(s) 2021

\begin{abstract}
A non-invasive sensor equipped with a programmable thermostat has been developed to assess in vivo the heat flow transmitted by conduction from human skin to the sensor thermostat. This device enables the assessment of the thermal properties of a $2 \times 2 \mathrm{~cm}^{2}$ skin surface with a thermal penetration depth of 3-4 mm. In this work, we report the thermal magnitudes recorded with this sensor in 6 different areas (temple, hand, abdomen, thigh, wrist and heel) of 6 healthy subjects of different genders and ages, which were measured under resting conditions. Heat flow and equivalent thermal resistance are proportionally related to each other and are highly variable in magnitude and different for each zone. The heat capacity is also different for each zone. The heat flow values varied from $362 \pm 17 \mathrm{~mW}$ at the temple to $36 \pm 12 \mathrm{~mW}$ at the heel for the same subject, when the sensor thermostat was set at $26^{\circ} \mathrm{C}$. The equivalent thermal resistance ranged from $23 \pm 2 \mathrm{~K} \mathrm{~W}^{-1}$ in the volar area of the wrist to $52 \pm 4 \mathrm{KW}^{-1}$ in the inner thigh area. The heat capacity varies from $4.8 \pm 0.4 \mathrm{~J} \mathrm{~K}^{-1}$ in the heel to $6.4 \pm 0.2 \mathrm{~J} \mathrm{~K}^{-1}$ in the abdomen. These magnitudes were also assessed over a $2 \times 1 \mathrm{~cm}^{2}$ second-degree burn scar in the volar area of the wrist. The scar area had 27.6 and $11.6 \%$ lower heat capacity and equivalent thermal resistance, respectively, allowing an increased heat flow in the injured area. This work is a preliminary study of the measurement capacity of this new instrument.
\end{abstract}

Keywords Direct calorimetry $\cdot$ Heat conduction calorimeters $\cdot$ Human heat flow $\cdot$ Medical calorimetry $\cdot$ Non-differential calorimeters $\cdot$ Physiology $\cdot$ Skin thermal properties

\section{Introduction}

The thermal state of a system is characterized by several magnitudes. The most relevant of such magnitudes is temperature, but the heat capacity and thermal conductance are also of interest. Temperature describes the internal energy of the system; heat capacity the energy necessary to increase its

Manuel Rodríguez de Rivera

manuel.rguezderivera@ulpgc.es

Pedro Jesús Rodríguez de Rivera pedrojrdrs@gmail.com

Miriam Rodríguez de Rivera miriam.mrdrs@gmail.com

Fabiola Socorro

fabiola.socorro@ulpgc.es

Gustavo Marrero Callicó gustavo@iuma.ulpgc.es

Jose A. L. Calbet

lopezcalbet@gmail.com temperature; and thermal conductance the heat flow that can be transferred through the system. In medicine, the assessment of skin temperature allows for detecting and monitoring fever [1] and some pathologies such as allergies [2], tendinitis [3], inflammations [4] and skin cancer [5].

Global measures of heat flow can be obtained by indirect calorimetry and are used to assess the resting metabolic rate

1 Department of Physics, University of Las Palmas de Gran Canaria, Campus Universitario de Tafira, 35017 Las Palmas de Gran Canaria, Spain

2 Institute for Applied Microelectronics (IUMA), University of Las Palmas de Gran Canaria, Campus Universitario de Tafira, 35017 Las Palmas de Gran Canaria, Spain

3 Department of Physical Education, University of Las Palmas de Gran Canaria, Campus Universitario de Tafira, 35017 Las Palmas de Gran Canaria, Spain

4 Department of Physical Performance, The Norwegian School of Sport Sciences, Oslo, Norway 
[6-8], which is altered in several conditions [9]. Heat flow sensors are often used to determine the heat flow in a specific area. These sensors have been used to study vasoconstriction and vasodilation [10], evaluate the thermoregulatory responses of the human body [11], design prototypes for research [12] and study of thermal comfort [13].

The heat capacity is usually determined from tissue samples using calorimetric instruments such as the differential scanning calorimeter (DSC) $[14,15]$. Thermal conductance can be determined by several techniques. One application of these data is the formulation of biothermal models [16-18]. The in vivo measurement of skin thermal conductance has been developed over several decades, although new methods are still being developed $[19,20]$. The in vivo measurement of heat capacity is a less developed field. One recent work is the Webb's ultra-fine contact matrix [21]. Generally, the response of the skin to a power dissipated by the sensor is studied. In the first case [20], the depth of thermal penetration is $0.9 \mathrm{~mm}$, and in the second [21], it is $0.5 \mathrm{~mm}$.

New sensors adaptable to the skin are currently being developed to obtain non-invasive thermal measurements in humans [22-24]. When an instrument is placed on the skin, the device alters the skin temperature, making technologies such as infrared thermography highly advantageous for temperature detection. However, determining the heat capacity requires providing energy to the system and measuring the change in temperature; similarly, determining the thermal conductance requires to elicit a heat transfer. In both cases, these measurements involve altering the system and assessing its response. This is the operating principle of several calorimeters and thermal analysis instruments. Thus, measuring skin temperature, heat capacity and thermal conductance at the same time can be counterproductive. When the thermal alteration produced is large, the heat capacity and thermal conductance will be determined more accurately, but at the cost of altering physiological processes. This problem may be circumvented by inducing a known and controlled alteration of temperature that allows obtaining the heat capacity and thermal conductance with an acceptable resolution, without significantly modifying the physiological processes.

For this purpose, we designed a calorimetric sensor to measure the heat flow, heat capacity and equivalent thermal resistance of a $4 \mathrm{~cm}^{2}$ skin area with a depth of thermal penetration of 3-4 $\mathrm{mm}$. The sensor is based on a thermopile with a programmable thermostat that has lateral thermal insulation to minimize the effects of convection and radiation during the measurement $[25,26]$.

The main objective of this investigation was to evaluate the measurement capacity of this new sensor, by conducting experiments in human subjects. In this work, we determined the variability of the thermal properties of the skin in different areas of the human body, in volunteers assessed under resting thermoneutral conditions. To get further insight into the potential applicability and sensitivity of the sensor, we also assessed these properties in a skin area with a seconddegree $2 \times 1 \mathrm{~cm}^{2}$ burn.

This article begins with the description of the experimental equipment and the method used to determine the heat flow and the thermal properties of the skin. The results obtained in healthy and resting subjects are next presented.

\section{Material and methods}

\section{Experimental system}

The characteristics of the sensor have been reported previously [25, 27]. Figure 1 shows a picture of the device (a), a section of the sensor (b) and a diagram of the calorimetric model (c).
Fig. 1 a Sensor at its base. b Sensor constructive diagram. c Model of the calorimetric sensor. (1) Measuring plate, (2) measuring thermopile, (3) thermostat, (4) cooling thermopile, (5) aluminium heatsink, (6) fan, (7) thermal insulation, (8) dissipation domain, (9) thermistor
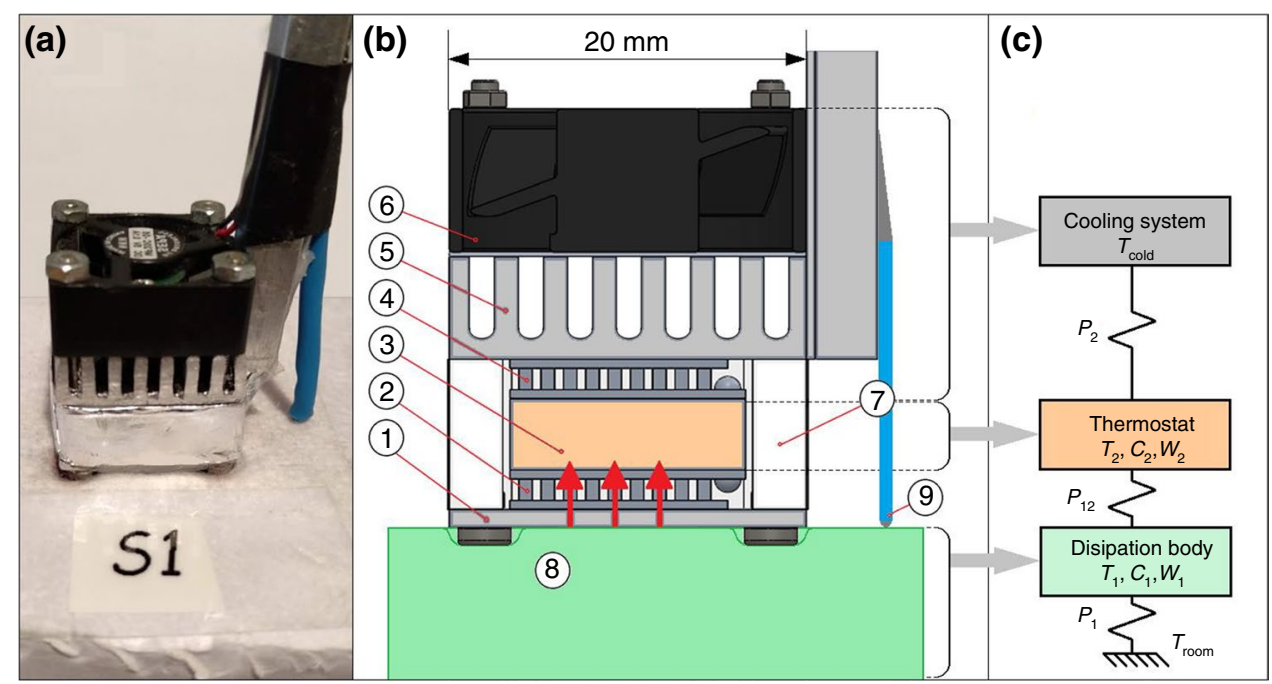
The main element of the sensor is a measurement thermopile that provides the calorimetric signal. This thermopile (part 2 in Fig. 1b) is located between a thermostat (part 3 in Fig. 1b) and an aluminium plate (part 1 in Fig. 1b). This aluminium plate is the part of the sensor that contacts with the skin (part 8 in Fig. 1b). The thermostat cooling system consists of a cooling thermopile, a heatsink and a fan (parts 4, 5 and 6 in Fig. 1b). A potential lateral heat transfer is minimized by a thermal insulation made of polystyrene covered with a reflective aluminium layer (part 7 in Fig. 1b). A thermistor (part 9 in Fig. 1b) measures the skin temperature in the vicinity of the sensor. The instrumentation required to operate the sensor is a programmable power supply (Agilent E3631A, 80 W Triple Output Power Supply, 6 V, 5 A and $25 \mathrm{~V}, 1 \mathrm{~A}$ ) and a data acquisition system (Agilent 34970A Data Acquisition/Data Logger Switch Unit and an Agilent 4901A 20-Channel Multiplexer). These instruments are connected to a Laptop through a GPIB bus (Agilent 82357B USB/GPIB Interface). A program developed in Microsoft Visual $\mathrm{C}++$ controls the instrument and stores all measured variables, with a sampling period of half a second.
Table 1 Values of the parameters of the model Eq. (1) obtained in the calibration base

\begin{tabular}{llllll}
\hline$C_{1} / \mathrm{J} \mathrm{K}^{-1}$ & $C_{2} / \mathrm{J} \mathrm{K}^{-1}$ & $\begin{array}{l}P_{1} / \\
\mathrm{mW} \mathrm{K}^{-1}\end{array}$ & $\begin{array}{l}P_{12} / \\
\mathrm{mW} \mathrm{K}^{-1}\end{array}$ & $\begin{array}{l}P_{2} / \\
\mathrm{mW} \mathrm{K}^{-1}\end{array}$ & $k / \mathrm{mV} \mathrm{K}^{-1}$ \\
\hline 3.00 & 3.98 & 33.38 & 96.07 & 64.83 & 19.02 \\
\hline
\end{tabular}

equations of the model that relate the inputs to the outputs are the result of the energy balance of each domain considered. The power developed in a domain is equal to the power that modifies the temperature of the domain plus the powers transmitted by conduction to the environment and neighbouring domains. The heat capacities of each domain are considered $C_{1}$ (the calibration base or human skin) and $C_{2}$ (the thermostat). The thermal conductance between domains $\left(P_{12}\right)$ and that between each domain and the environment $\left(P_{1}\right.$ and $P_{2}$ ) have also been considered. With these considerations, the system of Eq. (1) is obtained [27]. This system, written in the Laplace space, consists of six transfer functions that have the same denominator $Q(s)$, that is, the same poles and different gains and zeros.

$$
\left[\begin{array}{l}
\Delta Y(s) \\
\Delta T_{2}(s)
\end{array}\right]=\frac{1}{Q(s)}\left[\begin{array}{lll}
k\left(C_{2} s+P_{2}\right) & -k\left(C_{1} s+P_{1}\right) & k\left(P_{1} C_{2}-P_{2} C_{1}\right) s \\
P_{12} & C_{1} s+P_{12}+P_{1} & P_{2}\left(C_{1} s+P_{12}+P_{1}\right)+P_{1} P_{12}
\end{array}\right]\left[\begin{array}{l}
\Delta W_{1} \\
\Delta W_{2} \\
\Delta T_{0}
\end{array}\right]
$$

being, $Q(s)=\left(C_{1} s+P_{1}+P_{12}\right)\left(C_{2} s+P_{2}+P_{12}\right)-P_{12}^{2}$

\section{Sensor model}

The sensor works by controlling the thermostat temperature once in contact with the skin. To relate the thermal magnitudes (heat flow, heat capacity and equivalent thermal resistance) with the variables measured by the instrument, it was necessary to develop a sensor operating model. This model relates the inputs of the system, i.e., the power transmitted by the human body or heat flow $\left(W_{1}\right)$ and the power of the thermostat $\left(W_{2}\right)$, with the outputs, that is the calorimetric signal $(y)$ and the temperature of the thermostat $\left(T_{2}\right)$. We employed the so-called localized constants thermal model, which is commonly applied in thermal devices [28]. Figure $1 \mathrm{c}$ shows a schematic of the model in which three elements are considered: the cooling system, the thermostat and the place where dissipation takes place. Initially the sensor is located on its base to obtain the baseline signals. When the sensor reaches the steady state for a programmed thermostat temperature, the sensor is rapidly placed on the skin, which usually has a higher temperature. This increased in ambient temperature surrounding the sensor is represented by $\Delta T_{0}$, which is the third entry in the experimental system. The
Sensor calibration consists of determining the model parameters $\left(k, C_{1}, C_{2}, P_{1}, P_{12}\right.$ and $\left.P_{2}\right)$. All of them are invariant except the parameter $C_{1}$ that represents the heat capacity of the domain where $W_{1}$ dissipation occurs. When the sensor is at its base, $C_{1}$ is the heat capacity of the domain where the electrical calibration resistance is located. When the sensor is on the skin, $C_{1}$ represents the heat capacity of the area of the skin involved in the measurement. In order to calibrate the sensor, known heat dissipations are tested in the calibration base. Table 1 indicates the values obtained in the calibration.

\section{Device operation}

Initially the sensor is located on its calibration base. When the thermostat reaches the steady state for a temperature of $26^{\circ} \mathrm{C}$, the sensor is rapidly applied to the skin. For $5 \mathrm{~min}$, the thermostat remains at $26^{\circ} \mathrm{C}$. While the sensor is still on the skin, the temperature of the thermostat increases linearly to $36{ }^{\circ} \mathrm{C}$ at a rate of $4 \mathrm{~K}$ per minute $(2.5 \mathrm{~min})$. Finally, the sensor is kept on the skin for another 5 min with the thermostat at a constant temperature of $36^{\circ} \mathrm{C}$. For each thermostat temperature the heat flow of the human body is different. 


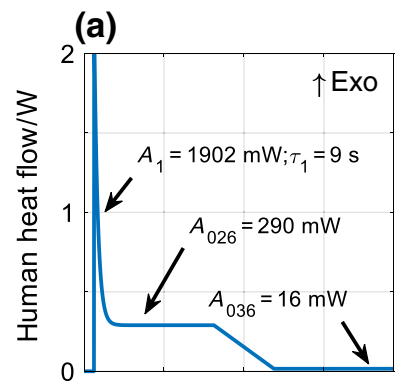

(b)

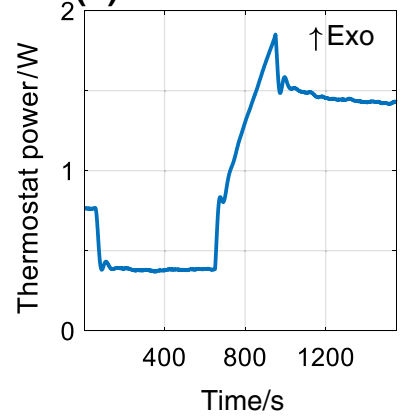

(c)

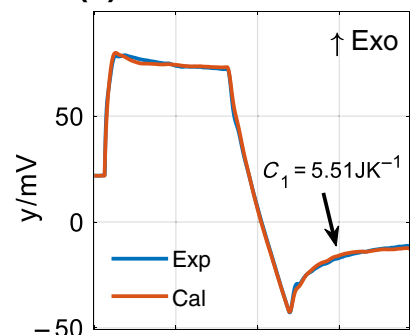

(d)

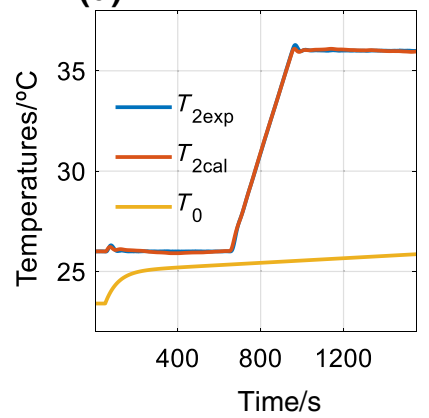

Fig. 2 Experimental measurement of heat flow in the volar face of the right wrist of a 62-year-old, healthy man. $\mathbf{a}$ and $\mathbf{b}$ Heat flow and power dissipated in the thermostat. c Experimental calorimetric signal (blue) and calculated (red) with the model. d Experimental temperature of the thermostat (blue) and calculated (red) with the model. $T_{0}$ is the ambient temperature surrounding the sensor. (Color figure online)

The heat flow and the thermal properties of the skin are determined using an iterative minimization algorithm [27] that adjusts the experimental curves with those obtained by the model given by Eq. (1). The experimental curves are the calorimetric signal, the power dissipated in the thermostat and the temperature of the thermostat. The invariant parameters of the model $\left(C_{2}, P_{1}, P_{12}, P_{2}\right.$ and $\left.k\right)$, whose values have been determined during the calibration process (Table 1), are also input data in the calculation algorithm. See an application example in Fig. 2 corresponding to a measurement carried out in the volar area of the right wrist of a healthy 62-year-old man at rest.

The calculated heat flow is shown in Fig. 2a and the power dissipated in the thermostat is shown in Fig. 2b. The fit between the experimental calorimetric signal and that calculated by the model is shown in Fig. 2c. In Fig. 2d, the fit between the experimental curve of the thermostat temperature and the calculated one is shown. The same figure represents the ambient temperature surrounding the sensor $\left(T_{0}\right)$. The ambient temperature was $23.4 \pm 0.1{ }^{\circ} \mathrm{C}$ for this measurement and the cooling system produced a decrease in temperature of $10{ }^{\circ} \mathrm{C}$, that is, $T_{\text {cold }}=T_{\text {room }}-10$ (see Fig. 1c).

\section{The heat flow}

The heat flow transferred from the skin to the sensor is the response to the disturbance produced by the placement of the sensor on the skin. A positive heat flow indicates transfer of energy from the human body to the sensor and vice versa, and a negative heat flow indicates gain of heat by the body. The disturbance produced by the sensor is systematic and depends on the temperature of the thermostat, which is programmable.

When the sensor is placed on the human body surface, the measured heat flow is proportional to the heat flow dissipated by the skin under natural circumstances. For example, in a subject that dissipates $87 \mathrm{~W}$ at rest, $20 \%$ lost by evaporation and $25 \%$ by respiration [29], the heat flow transferred by conduction through the skin is $48 \mathrm{~W}$. Assuming a body surface area of $1.7 \mathrm{~m}^{2}$, we obtain $10-12 \mathrm{~mW}$ in $4 \mathrm{~cm}^{2}$. This corresponds to the heat flow in its baseline state when the sensor is not in contact with the skin. However, the heat flow measured with the sensor in contact with the skin is about $210 \mathrm{~mW}$ for the thermostat at $26{ }^{\circ} \mathrm{C}$. This experimental result is explained by the increase in the heat flow transmitted by conduction, which is proportional to the difference in temperatures and inversely proportional to the thermal resistance of the system. In the case of the skin-sensor thermostat system, this thermal resistance is $10.41 \mathrm{~K} \mathrm{~W}^{-1}$ [27]. In the skin-air system, for a closed environment with no perceptible air current, the thermal resistance is $\sim 220 \mathrm{~K} \mathrm{~W}^{-1}$ [30]. Consequently, the heat flow measured by the sensor is around 20 times higher observed under natural conditions, i.e., for a skin-to-air transfer. This is the reason why when touching a metal surface, some cold is felt, even if the metal is at a temperature equal to that of the environment. This sensation of cold is due to net heat flow transferred from the skin to the metal facilitated by the high thermal conductivity of metals.

The initial transient of the heat flow (Fig. 2a) is represented by a decreasing exponential of amplitude $A_{1}$ and time constant $\tau_{1}$. This transient is due to the instantaneous contact between two surfaces at different temperatures: the skin surface and that of the sensor. The steady-state heat flow for the thermostat temperature of $26{ }^{\circ} \mathrm{C}$ is $A_{026}$. We assume that increasing the thermostat temperature produces a linear decrease in heat flow. When the final temperature of the thermostat is kept constant at $36{ }^{\circ} \mathrm{C}$, we consider that the heat flow remains constant at a value $A_{036}$. Equation (2) represents the hypothesis considered for the heat flow $W_{1}(t)$.

$$
\begin{array}{ll}
W_{1}(t)=0 & \text { for } t<t_{1} \\
W_{1}(t)=A_{1} \cdot \exp \left(-\left(t-t_{1}\right) / \tau_{1}\right)+A_{026} & \text { for } t_{1} \leq t \leq t_{2} \\
W_{1}(t)=A_{026}+\left(A_{036}-A_{026}\right) \cdot\left(t-t_{2}\right) /\left(t_{3}-t_{2}\right) & \text { for } t_{2} \leq t \leq t_{3} \\
W_{1}(t)=A_{036} & \text { for } t_{3} \leq t \leq t_{\text {end }}
\end{array}
$$




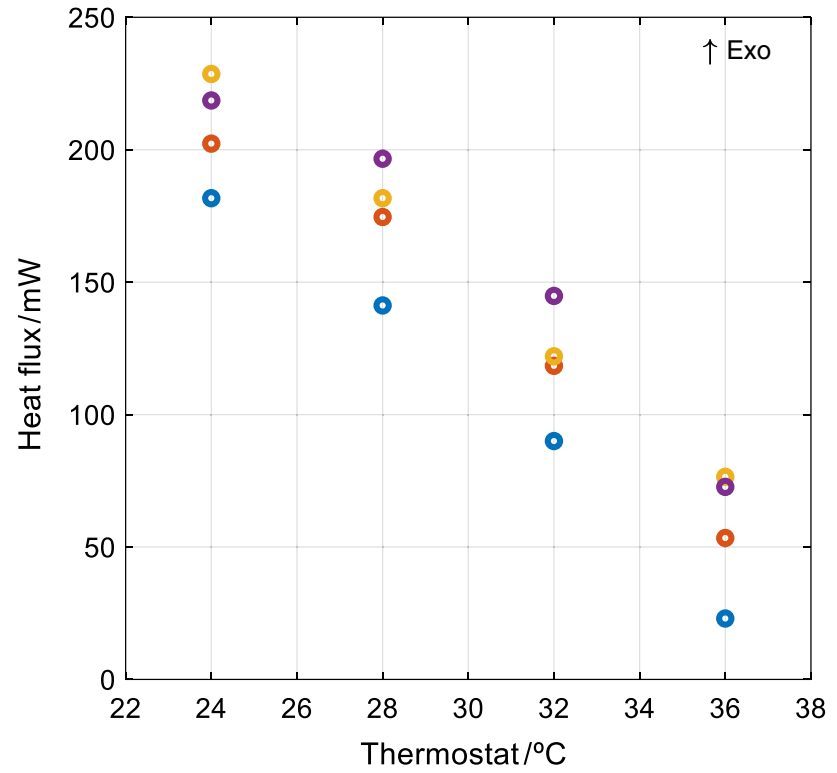

Fig. 3 Heat flow in the dorsal area of the hand of a healthy 24-year-old man at rest. The circles of the same colour are consecutive measurements, spaced $30 \mathrm{~min}$ apart. Each measurement corresponds to thermostat temperatures of $24,28,32$ and $36{ }^{\circ} \mathrm{C}$. $T_{\text {room }}=24.4 \pm 0.2^{\circ} \mathrm{C}$. (Color figure online)

In Eq. $2, t_{1}$ is the instant at which the device is applied on the skin, $t_{2}$ is the instant at which the temperature of the thermostat begins to increase linearly, and $t_{3}$ is the instant at which the linear variation ends and the temperature remains constant. Lastly, the final instant of the measurement is represented by $t_{\text {end }}$.

\section{The equivalent thermal resistance}

In different measurements taken with the thermostat at constant temperature [26], it was verified that the cutaneous heat flow decreases linearly when the thermostat temperature increases. Figure 3 shows an example of this experimental fact.

In Fig. 3, the heat flow in the dorsal area of the hand of a healthy 24-year-old man at rest is represented for different thermostat temperatures $\left(24,28,32\right.$ and $\left.36{ }^{\circ} \mathrm{C}\right)$. Circles of the same colour are consecutive measurements spaced 30 min apart. This linear relationship between the thermostat temperature and the heat flow allows defining an equivalent thermal resistance $\left(R_{\mathrm{eq}}\right)$ of the skin area as the quotient between the increase in the thermostat temperature $\left(T_{2 \mathrm{~b}}-T_{2 \mathrm{a}}\right)$ and the difference of heat flow at each temperature $\left(W_{1 \mathrm{a}}-W_{1 \mathrm{~b}}\right)$. From this value, we subtract the thermal resistance of the sensor: $R_{\text {sensor }}=1 / P_{12}$. Equation (3) expresses its application to the experimental measure represented in Fig. 2.
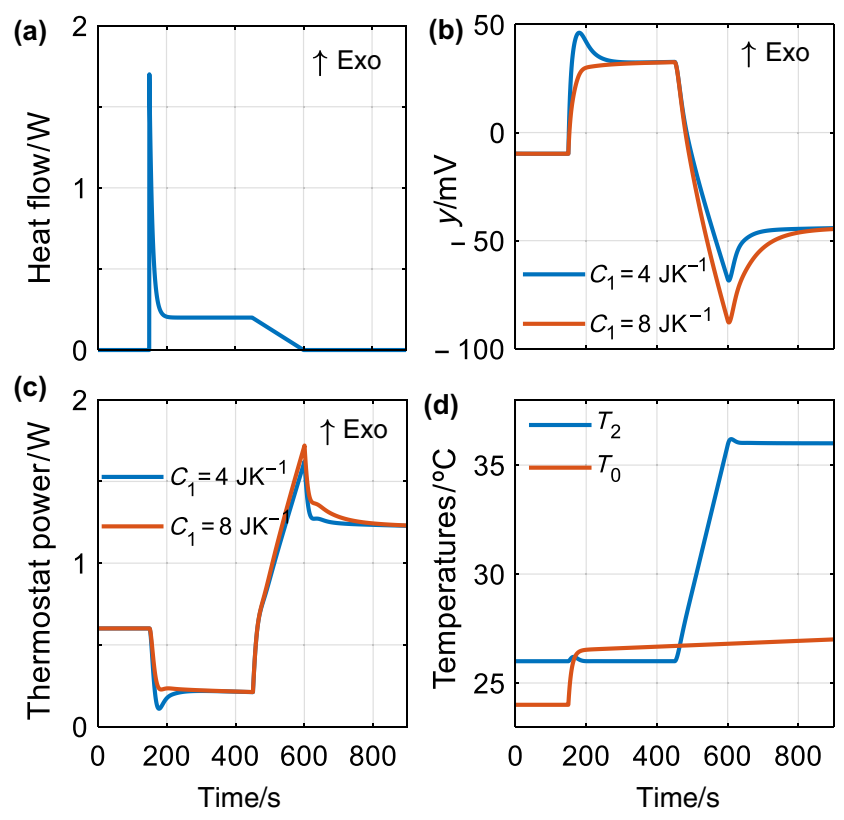

Fig. 4 Sensor operation simulation for $C_{1}=4 \mathrm{~J} \mathrm{~K}^{-1}$ and $C_{1}=8 \mathrm{~J} \mathrm{~K}^{-1}$. a Heat flow, $\mathbf{b}$ power dissipated in the thermostat, $\mathbf{c}$ calorimetric signal and $\mathbf{d}$ temperature of thermostat $T_{2}$ and temperature surrounding the sensor $T_{0}$

$R_{\mathrm{eq}}=\frac{T_{2 \mathrm{~b}}-T_{2 \mathrm{a}}}{W_{1 \mathrm{a}}-W_{1 \mathrm{~b}}}-R_{\text {sensor }}=\frac{36-26}{0.290-0.016}-10.41=26.086 \mathrm{~K} \mathrm{~W}^{-1}$

\section{The heat capacity}

Currently, the heat capacity of a substance is mainly determined using differential scanning calorimetry (DSC), whose operation consists in causing a linear variation of the substance's temperature. This gives rise to a step-type calorimetric signal whose amplitude is constant and proportional to the heat capacity and the rate of the temperature change. Although our sensor operates in a similar way, it is nondifferential and therefore the calorimetric response is a stepin ramp.

Figure 4 shows a simulation of the sensor operation for the case of two different heat capacities $C_{1}=4 \mathrm{~J} \mathrm{~K}^{-1}$ and $C_{1}=8 \mathrm{~J} \mathrm{~K}^{-1}$. In Fig. $4 \mathrm{~b}$, the power $W_{2}(t)$ required to maintain the thermostat temperature is shown. The lower the heat capacity, the less the energy is needed to increase the temperature. Figure $4 \mathrm{c}$ shows the difference between the calorimetric curves for each heat capacity. These differences allow obtaining $C_{1}$. In this simulation, we have considered the amplitude of the initial heat flow transient $A_{1}=1.5 \mathrm{~W}$ with a time constant $\tau_{1}=9 \mathrm{~s}$ (see Eq. (2)). The heat flow considered for $26^{\circ} \mathrm{C}$ is $200 \mathrm{~mW}$ and $0 \mathrm{~mW}$ for $36^{\circ} \mathrm{C}$. The variation of the thermostat temperature is from 26 to $36^{\circ} \mathrm{C}$ in $150 \mathrm{~s}$. 
An ambient temperature of $T_{\text {room }}=24{ }^{\circ} \mathrm{C}$ is considered, and the cooling system produces a decrease of $6.5^{\circ} \mathrm{C}$, that is, $T_{\text {cold }}=17.5^{\circ} \mathrm{C}$. The simulation generates signals similar to the experimental ones. Equation (1) relates the signals to the heat flow through the model parameters (Table 1). The calculation algorithm determines the heat flow and the heat capacity $C_{1}$, which depends on the measured area. For the case of the experimental measure represented in Fig. 2, $C_{1}=5.51 \mathrm{~J} \mathrm{~K}^{-1}$.

Table 2 Anthropometric characteristics of subjects

\begin{tabular}{lllll}
\hline Subject & Sex & Age/years & Mass $/ \mathrm{kg}$ & Height $/ \mathrm{m}$ \\
\hline 1 & Male & 62 & 71 & 1.60 \\
2 & Male & 29 & 68 & 1.72 \\
3 & Male & 26 & 83 & 1.77 \\
4 & Female & 57 & 68 & 1.66 \\
5 & Female & 31 & 74 & 1.49 \\
6 & Female & 23 & 53 & 1.61 \\
\hline
\end{tabular}

\section{Data analysis}

Experimental results were obtained in six areas of the skin of the human body (temple, hand, abdomen, thigh, heel and wrist) in 6 healthy subjects, at rest, sitting and dressed normally. The blood pressure and heart rate were measured before and after each measurement, obtaining unaltered normal resting values in all cases (Omron M3 Tensiometer HEM-7154-E). The ambient temperature $\left(22-24{ }^{\circ} \mathrm{C}\right)$ and relative humidity $(50-60 \%)$ were also measured (Digoo Weather Station DG-TH8380). Measurements were taken in a closed room, without perceptible air currents. Each measurement was repeated four times to determine its uncertainty. Experimental data are presented as mean \pm standard deviation (SD). The linear relationships were assessed by simple regression. The degree of linearity and goodness of fit were assessed by determining Pearson's correlation coefficient, the root mean squared error (RMSE) and the adjusted $R^{2}$. For the assessment of differences between samples, the Welch's $t$ test is carried out. The test output is 1 when the difference between
Table 3 Body heat flow for each thermostat temperature, $A_{026}$ and $A_{036}$, equivalent thermal resistance $R_{\text {eq }}$ and heat capacity $C_{1}$. Mean values \pm standard deviation are shown for each subject and zone

\begin{tabular}{|c|c|c|c|c|c|c|}
\hline Zone & Subject 1 & Subject 2 & Subject 3 & Subject 4 & Subject 5 & Subject 6 \\
\hline \multicolumn{7}{|c|}{ Body heat flow $A_{026} / \mathrm{mW}$ (thermostat at $26^{\circ} \mathrm{C}$ ) } \\
\hline Temple & $323 \pm 15$ & $279 \pm 6$ & $362 \pm 17$ & $294 \pm 15$ & $339 \pm 13$ & $293 \pm 8$ \\
\hline Hand & $282 \pm 24$ & $171 \pm 38$ & $241 \pm 14$ & $300 \pm 18$ & $207 \pm 42$ & $221 \pm 22$ \\
\hline Abdomen & $278 \pm 8$ & $224 \pm 18$ & $198 \pm 24$ & $195 \pm 29$ & $205 \pm 17$ & $341 \pm 29$ \\
\hline Thigh & $195 \pm 22$ & $200 \pm 7$ & $180 \pm 11$ & $166 \pm 20$ & $160 \pm 17$ & $212 \pm 38$ \\
\hline Heel & $84 \pm 18$ & $-40 \pm 22$ & $36 \pm 12$ & $105 \pm 22$ & $6 \pm 18$ & $19 \pm 28$ \\
\hline Wrist & $296 \pm 20$ & - & $322 \pm 25$ & - & - & - \\
\hline \multicolumn{7}{|c|}{ Body heat flow $A_{036} / \mathrm{mW}$ (thermostat at $36{ }^{\circ} \mathrm{C}$ ) } \\
\hline Temple & $74 \pm 12$ & $64 \pm 4$ & $107 \pm 5$ & $78 \pm 7$ & $130 \pm 7$ & $60 \pm 6$ \\
\hline Hand & $35 \pm 18$ & $-58 \pm 32$ & $15 \pm 7$ & $38 \pm 14$ & $-12 \pm 41$ & $-27 \pm 24$ \\
\hline Abdomen & $52 \pm 13$ & $26 \pm 10$ & $-8 \pm 43$ & $-28 \pm 28$ & $12 \pm 18$ & $88 \pm 13$ \\
\hline Thigh & $9 \pm 12$ & $20 \pm 10$ & $-11 \pm 5$ & $-20 \pm 4$ & $-2 \pm 10$ & $42 \pm 28$ \\
\hline Heel & $-109 \pm 15$ & $-222 \pm 17$ & $-177 \pm 20$ & $-109 \pm 21$ & $-177 \pm 14$ & $-172 \pm 16$ \\
\hline Wrist & $29 \pm 15$ & - & $29 \pm 23$ & - & - & - \\
\hline \multicolumn{7}{|c|}{ Equivalent thermal resistance, $R_{\mathrm{eq}} / \mathrm{W} \mathrm{K}^{-1}$} \\
\hline Temple & $29.9 \pm 2.4$ & $36.3 \pm 1.7$ & $29.0 \pm 2.7$ & $36.1 \pm 3.6$ & $37.5 \pm 2.5$ & $32.6 \pm 2.1$ \\
\hline Hand & $28.9 \pm 1.3$ & $33.5 \pm 3.4$ & $33.9 \pm 2.1$ & $27.8 \pm 5.1$ & $35.3 \pm 1.9$ & $30.4 \pm 5.0$ \\
\hline Abdomen & $34.0 \pm 1.4$ & $40.0 \pm 2.9$ & $32.3 \pm 1.8$ & $34.5 \pm 1.4$ & $42.1 \pm 5.6$ & $29.2 \pm 2.7$ \\
\hline Thigh & $43.4 \pm 3.2$ & $45.2 \pm 2.2$ & $42.2 \pm 2.2$ & $43.8 \pm 5.5$ & $51.6 \pm 3.9$ & $48.8 \pm 5.2$ \\
\hline Heel & $41.4 \pm 1.2$ & $44.8 \pm 3.0$ & $38.1 \pm 2.3$ & $36.2 \pm 0.4$ & $44.3 \pm 2.4$ & $42.1 \pm 3.5$ \\
\hline Wrist & $27.3 \pm 2.4$ & - & $23.3 \pm 1.6$ & - & - & - \\
\hline \multicolumn{7}{|c|}{ Heat capacity, $C_{1} / \mathrm{J} \mathrm{K}^{-1}$} \\
\hline Temple & $5.81 \pm 0.24$ & $5.94 \pm 0.31$ & $5.47 \pm 0.31$ & $5.53 \pm 0.13$ & $4.68 \pm 0.41$ & $6.27 \pm 0.10$ \\
\hline Hand & $5.43 \pm 0.49$ & $5.32 \pm 0.21$ & $5.36 \pm 0.16$ & $5.05 \pm 0.53$ & $5.34 \pm 0.19$ & $5.59 \pm 0.07$ \\
\hline Abdomen & $5.58 \pm 0.30$ & $5.69 \pm 0.32$ & $6.30 \pm 0.19$ & $6.38 \pm 0.17$ & $5.83 \pm 0.42$ & $5.96 \pm 0.40$ \\
\hline Thigh & $5.80 \pm 0.06$ & $5.40 \pm 0.18$ & $5.47 \pm 0.09$ & $5.79 \pm 0.16$ & $5.77 \pm 0.16$ & $5.41 \pm 0.22$ \\
\hline Heel & $4.98 \pm 0.22$ & $4.76 \pm 0.36$ & $4.92 \pm 0.14$ & $5.18 \pm 0.24$ & $4.81 \pm 0.43$ & $4.97 \pm 0.20$ \\
\hline Wrist & $5.67 \pm 0.39$ & - & $6.08 \pm 0.22$ & - & - & - \\
\hline
\end{tabular}



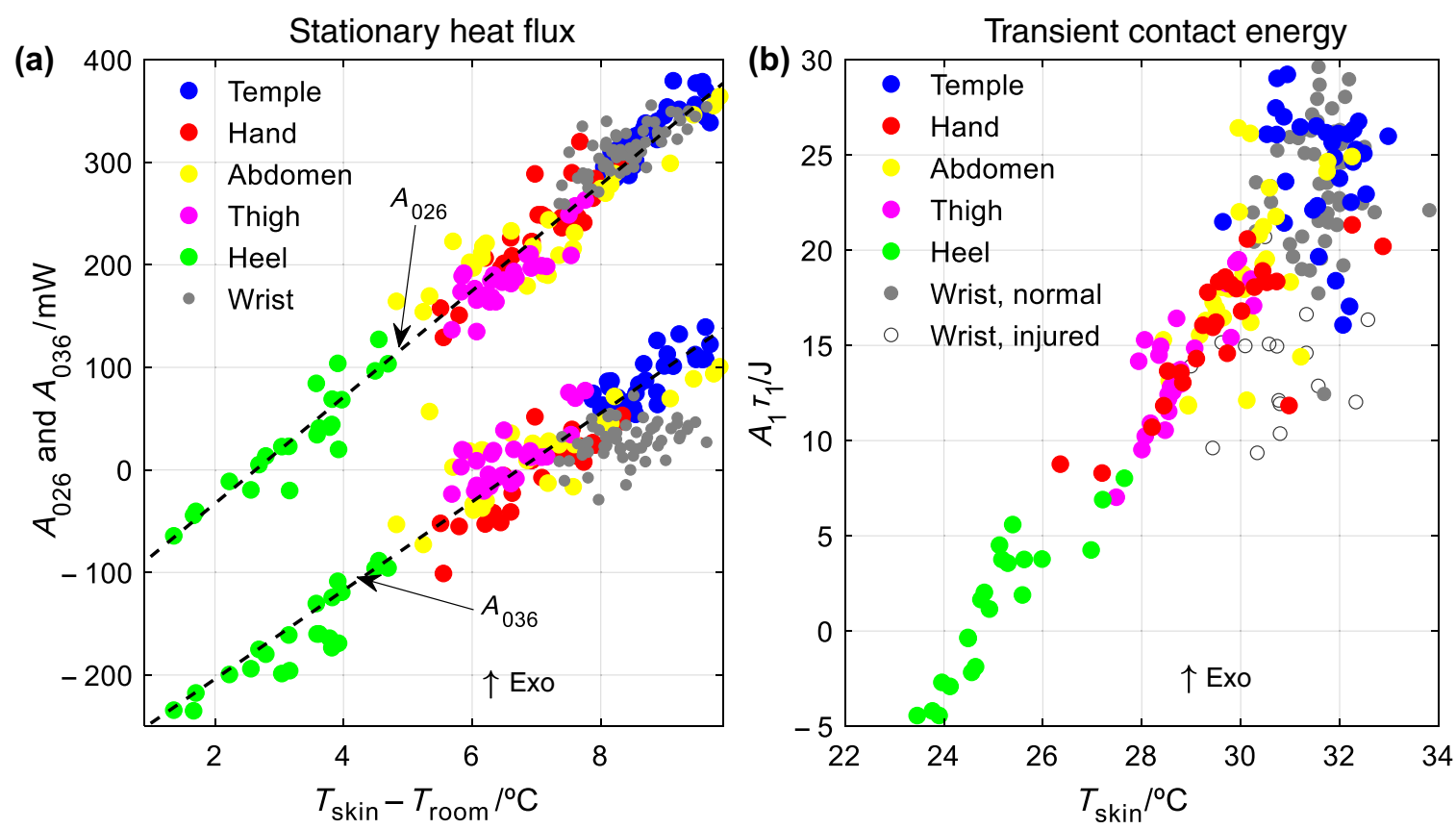

Fig. 5 a Heat flow for different thermostat temperatures of $26{ }^{\circ} \mathrm{C}$ and $36{ }^{\circ} \mathrm{C}\left(A_{026}\right.$ and $\left.A_{036}\right)$ versus $\left(T_{\text {skin }}-T_{\text {room }}\right)$. Linear adjustment parameters are indicated in Table 4 . $\mathbf{b}$ Transient contact energy $\left(A_{1} \tau_{1}\right)$ versus $\left(T_{\text {skin }}\right)$. Average $T_{\text {room }}=23{ }^{\circ} \mathrm{C}$

samples is significant and 0 when it is not. In all cases, the significance level was set at $p<0.005$.

\section{Results and discussion}

This section presents the experimental results. Table 2 shows the anthropometric characteristics of the subjects. The thermal results obtained are shown in Table 3 and discussed below. Section 4 presents a temporal study of the second-degree burn on the wrist of subject 1.

\section{Heat flow discussion $\left(A_{026}, A_{036}, A_{1}\right.$ and $\left.\tau_{1}\right)$}

Applying the sensor to the skin causes a drop of skin temperature in the measurement area, since initially the thermostat is at $26{ }^{\circ} \mathrm{C}$. The thermistor installed in the device reads the skin temperature during the measurement. We defined $T_{\text {skin }}$ as the mean value of the skin temperature when the thermostat is at $26{ }^{\circ} \mathrm{C}$. This temperature is slightly lower than the physiological skin temperature at rest in a thermoneutral environment. The $T_{\text {skin }}$ values were $31.6 \pm 0.7{ }^{\circ} \mathrm{C}$ at the temple, $31.5 \pm 0.7{ }^{\circ} \mathrm{C}$ at the wrist, $30.1 \pm 0.9^{\circ} \mathrm{C}$ at the thigh, $29.6 \pm 1.3{ }^{\circ} \mathrm{C}$ at the hand, $28.8 \pm 0.7^{\circ} \mathrm{C}$ at the thigh and $25.1 \pm 1.1^{\circ} \mathrm{C}$ at the heel.

In Fig. 5a, the values of the heat flow for the two thermostat temperatures $\left(A_{026}\right.$ and $\left.A_{036}\right)$ are represented versus the temperature difference between skin and environment, $T_{\text {skin }}-T_{\text {room }}$. In Fig. 5b, the transient contact energy that is transferred from the sensor to the skin (or vice versa) is represented as a function of the skin temperature. This energy is determined as the integral of the heat flow above the stable value, whose value is the product of $A_{1} \tau_{1}$ (see Eq. (2)). This integral corresponds to the area under the initial peak of the heat flow $W_{1}$ (see Fig. 2a).

As shown in Fig. 5a, heat flow was greater when the thermostat is at 26 than $36{ }^{\circ} \mathrm{C}$. When the thermostat was set at $26{ }^{\circ} \mathrm{C}$, all values were positive except for some cases in the heel. At $36{ }^{\circ} \mathrm{C}$, all values at the temple were
Table 4 Parameters of the linear adjustment of the heat flow (Fig. 5a)

\begin{tabular}{|c|c|c|c|c|}
\hline$T_{\text {Thermostat }} /{ }^{\circ} \mathrm{C}$ & $a / \mathrm{mW}$ & $b / \mathrm{mW} \mathrm{K}^{-1}$ & Adjusted $R^{2}$ & $\mathrm{RMSE} / \mathrm{mW}$ \\
\hline $\begin{array}{l}A_{026}=a+b 26 \\
\left(T_{\text {skin }}-T_{\text {room }}\right)\end{array}$ & -136 & 52 & 0.95 & 22 \\
\hline $\begin{array}{l}A_{036}=a+b 36 \\
\left(T_{\text {skin }}-T_{\text {room }}\right)\end{array}$ & -290 & 43 & 0.91 & 25 \\
\hline
\end{tabular}

RMSE root mean square error 
positive; in the abdomen, hand and thigh, $60 \%$ were positive, in the wrist $85 \%$ are positive, and in the heel, all were negative. On the other hand, the lowest skin temperature was measured at the heel (lower values) and the highest at the temple (greater values).

The heat flow can be positive, even at skin temperatures below that of the thermostat. This occurs because the sensor stabilizes with a nearby area below the skin surface which must be at a higher temperature than the surface of the skin and the thermostat. As expected, the heat flow is proportional to the $T_{\text {skin }}-T_{\text {room }}$ temperature difference. The regression lines are shown in Fig. 5a and the parameters of each adjustment in Table 4.

The heat flow was different in each zone. The mean value, for the thermostat at $26^{\circ} \mathrm{C}$, considering all the subjects, is $315 \mathrm{~mW}$ at the temple, $309 \mathrm{~mW}$ at the wrist, $240 \mathrm{~mW}$ at the abdomen, $237 \mathrm{~mW}$ at the hand, $186 \mathrm{~mW}$ at the thigh and $48 \mathrm{~mW}$ at the heel. The greatest heat flow occurred in the temple and the lowest in the lower extremity (thigh and heel). On average, the greatest variability of heat flow was detected in the arm and the smaller in the temple.

There were also sex and age differences. On average, men dissipate about $8 \%$ more than women, although in this study this difference is not significant. Regarding age, in the abdomen, temple and thigh, dissipations were similar in all subjects. However, in the hand, heat flow in older ( $>50$ years, $n=2$ ) is $34 \%$ greater than in younger people $(<30$ years, $n=4)$. And in the heel, young subjects had a heat flow close to 0 or negative (mean $3 \mathrm{~mW}$ ), while in older subjects it is remarkably higher (mean $93 \mathrm{~mW}$ ). Welch's $t$ test has been used to evaluate the difference between samples for each zone (see Table 5).

Regarding the transient contact energy, it is also proportional to the temperature of the skin, showing a behaviour similar to the that of the stationary heat flow. This magnitude is obtained from a transitory phenomenon, and therefore, its variability is very high.

These observations are consistent with the hypotheses on skin thermodynamics put forward by other authors [30-33].

\section{Heat capacity discussion $\left(C_{1}\right)$}

Figure 6 shows the heat capacity the skin areas tested versus skin temperature, $T_{\text {skin }}$. Each experimental cloud of points is represented by different colours. A series of measurements taken in the first week on a second-degree burn on the wrist is also depicted. The characteristics and the study of this lesion are described in "Temporal thermal study of a seconddegree burn on the wrist" section.

The heat capacity ranges from 4.1 to $6.6 \mathrm{~J} \mathrm{~K}^{-1}$. In all areas, the standard deviation is similar, although it is slightly higher at the temple. The thermal properties measured by the sensor are a combination of the thermal properties of the tissues that compose the studied area. Table 6 shows some reference values for specific heat capacity, thermal conductivity and density of different tissues. We define the thermal penetration depth as the depth of the tisular region whose temperature is modified by the instrument [20]. This value indicates the spatial zone of the skin involved in the measurement. The thermal penetration depth of the sensor can be estimated from the relation between the heat capacity assessed by the sensor and the heat capacity reference of the tissue. A simplified estimation can be done by considering a $2 \times 2 \mathrm{~cm}^{2}$ prism with a depth of $0.3-0.4 \mathrm{~cm}$ [27]. Considering an average value of specific heat capacity of $3.39 \mathrm{~kJ} \mathrm{~kg}^{-1} \mathrm{~K}^{-1}$ and an average density of the skin of $1.11 \mathrm{~g} \mathrm{~cm}^{-3}$ (Table 6), we obtained, for each depth (0.3 and $0.4 \mathrm{~cm}$ ), heat capacities of $4.5-6.0 \mathrm{~J} \mathrm{~K}^{-1}$, values of the same order of magnitude that the experimental results obtained.
Table 5 Heat flow comparison (thermostat at $26^{\circ} \mathrm{C}$ ) between old $\left(x_{1}\right)$ and young $\left(x_{2}\right)$ subjects for each zone $\left(n_{\mathrm{i}}\right.$ is the sample size)

Table 6 Values of heat capacity, thermal conductivity and density of different tissues [34]

\begin{tabular}{|c|c|c|c|c|c|c|}
\hline \multirow[t]{2}{*}{ Zone } & \multicolumn{2}{|c|}{ Subjects $>50$ years $\left(x_{1}\right)$} & \multicolumn{2}{|c|}{ Subjects $30<$ years $\left(x_{2}\right)$} & \multirow[t]{2}{*}{ Welch's $t$ test } & \multirow[t]{2}{*}{$p$ value } \\
\hline & $n_{1}$ & Heat flow $/ \mathrm{mW}$ & $n_{2}$ & Heat flow $/ \mathrm{mW}$ & & \\
\hline Temple & 12 & 313 & 20 & 327 & 0 & $p>0.005$ \\
\hline Hand & 7 & 289 & 20 & 216 & 1 & $4.5 \times 10^{-5}$ \\
\hline Abdomen & 7 & 242 & 24 & 228 & 0 & $p>0.005$ \\
\hline Thigh & 8 & 181 & 20 & 193 & 0 & $p>0.005$ \\
\hline Heel & 7 & 93 & 15 & 3 & 1 & $3.5 \times 10^{-6}$ \\
\hline
\end{tabular}

\begin{tabular}{lllllll}
\hline Property & Units & Skin & Fat & Muscle & Blood & Bone (cortical) \\
\hline Specific heat capacity & $\mathrm{kJ} \mathrm{kg}^{-1} \mathrm{~K}^{-1}$ & 3.39 & 2.35 & 3.42 & 3.62 & 1.31 \\
Thermal conductivity & $\mathrm{Wm}^{-1} \mathrm{~K}^{-1}$ & 0.37 & 0.21 & 0.49 & 0.52 & 0.32 \\
Density & $\mathrm{g} \mathrm{cm}^{-3}$ & 1.11 & 0.91 & 1.09 & 1.05 & 1.91 \\
\hline
\end{tabular}


Fig. 6 Heat capacity, $C_{1}$ versus skin temperature $\left(T_{\text {skin }}\right)$ for each area of the human body (temple, hand, abdomen, thigh, wrist and heel). The red outlined cloud contains the measurements taken in an area of the wrist that suffered a second-degree burn. Average $T_{\text {room }}=23^{\circ} \mathrm{C}$. $($ Color figure online)

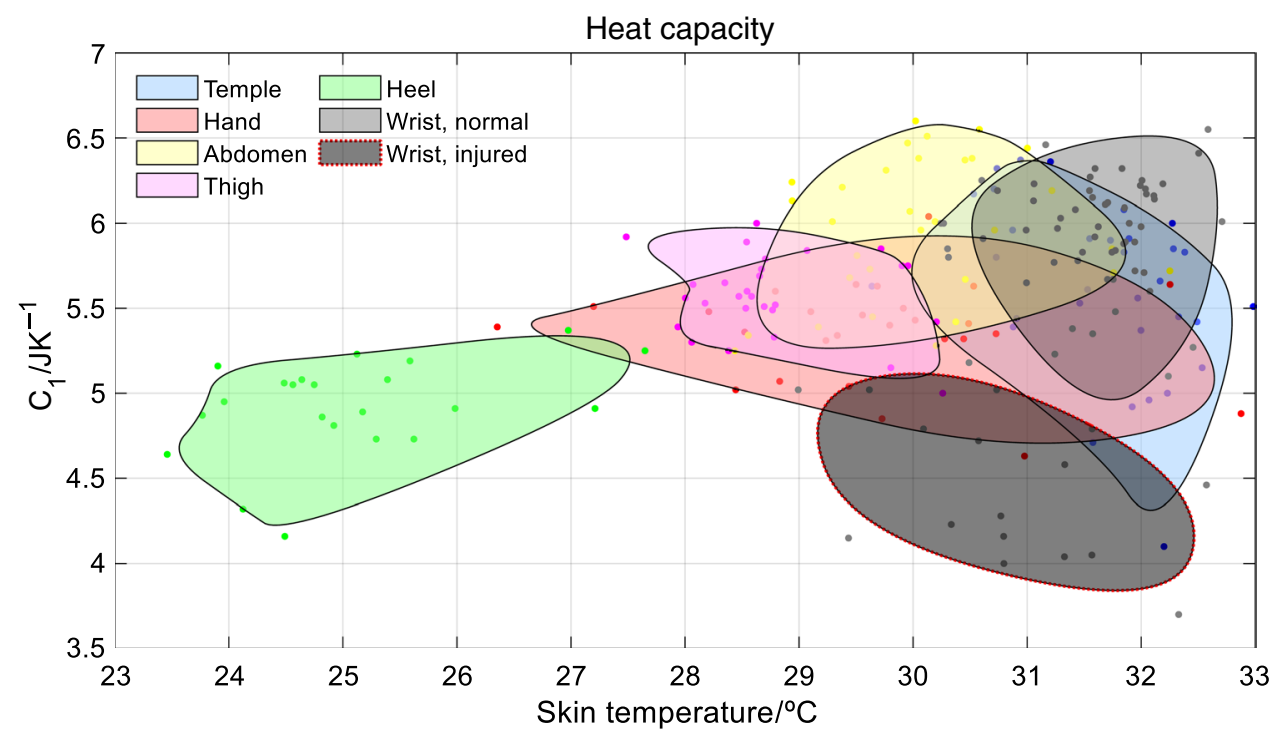

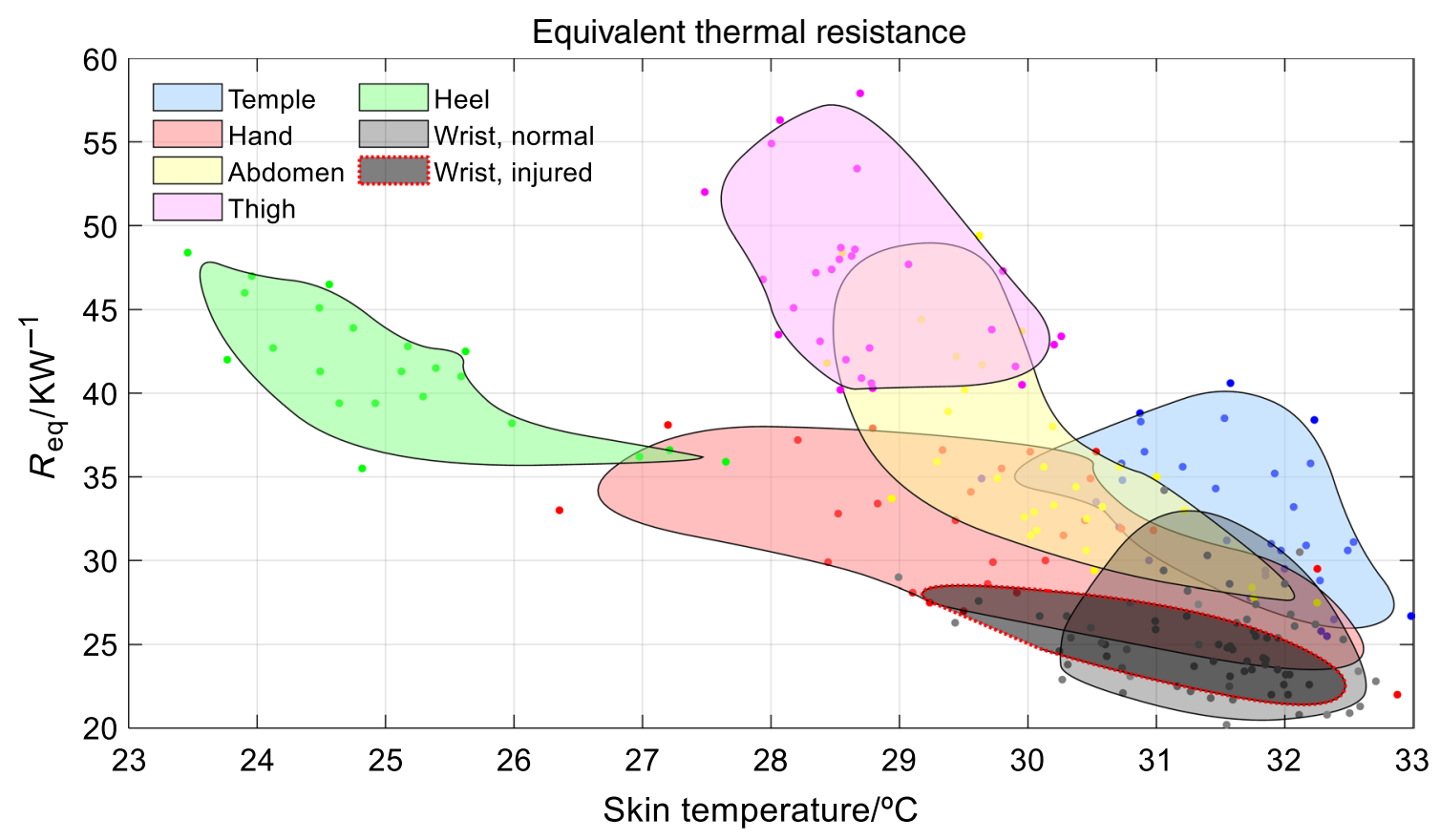

Fig. 7 Equivalent thermal resistance, $R_{\text {eq }}$, versus skin temperature $\left(T_{\text {skin }}\right)$ for each surface tested (temple, hand, abdomen, thigh, wrist and heel). The red outlined cloud contains the measurements taken

As shown in Fig. 6, each zone has a different heat capacity. The mean value of the heat capacity is $4.9 \mathrm{~J} \mathrm{~K}^{-1}$ in the heel, 5.4 $\mathrm{J} \mathrm{K}^{-1}$ in the hand, 5.6 $\mathrm{J} \mathrm{K}^{-1}$ in the temple and thigh, and $5.9 \mathrm{~J} \mathrm{~K}^{-1}$ in the abdomen and wrist. In view of these results, it is more likely to obtain similar values of heat capacity in identical areas of different subjects than in different areas of the same subject. Note that the standard deviation is not very different from the difference of the mean values. For this reason, to establish rigorous correlations, in an area of the wrist that suffered a second-degree burn. Average $T_{\text {room }}=23{ }^{\circ} \mathrm{C}$. (Color figure online)

it would be desirable to carry out experiments in a larger number of subjects. No direct correlations are observed between heat capacity and heat flow, skin temperature or thermal resistance.

However, there are some concordances with the reference values in Table 6 . The lowest values of heat capacity correspond to measurements on the hand, heel and some on the temple (green, red and blue areas in Fig. 6). Precisely, the dorsal area of the hand and the temple are closer to the 
metacarpal and skull cortical bone, respectively, which have a very low heat capacity (see Table 6). It is possible that the high variability of the measurements at the temple is related to the proximity to the temporal artery as well as to variations in skin blood flow. The heel also has a low calorific capacity, a consistent result as it is an area poorly perfused, with a thicker stratum corneum and abundant subcutaneous fat. The low heat capacity of the heel has already been reported in other works $[21,23]$. The anteromedial aspect of the thigh, the volar area of the wrist and abdomen (right flank) have a higher heat capacity, which may relate to their greater perfusion.

\section{Equivalent thermal resistance discussion $\left(R_{\mathrm{eq}}\right)$}

In Fig. 7, the equivalent thermal resistance is shown for each area of the human body versus skin temperature. As in the previous figure, each cloud of points is delimited by coloured line. The series of measurements corresponding to the second-degree burn is also represented, which will be discussed in "Temporal thermal study of a second-degree burn on the wrist" section.

The equivalent thermal resistance ranges from 20 to $58 \mathrm{~K} \mathrm{~W}^{-1}$, and each surface of the human body has a different equivalent thermal resistance. The mean value is $34.4 \mathrm{~K} \mathrm{~W}^{-1}$ in the temple, $32.0 \mathrm{KW}^{-1}$ in the hand, $34.3 \mathrm{~K} \mathrm{~W}^{-1}$ in the abdomen, $44.5 \mathrm{~K} \mathrm{~W}^{-1}$ in the thigh, $41.8 \mathrm{~K} \mathrm{~W}^{-1}$ in the heel and $27.3 \mathrm{~K} \mathrm{~W}^{-1}$ in the wrist. Some concordance is observed between these results and the reference data in Table 6 . The areas with the highest thermal resistance (heel, thigh and abdomen) correspond to regions that have a higher percentage of fat than the other areas (wrist, temple and hand). Body fat has low thermal conductivity, which implies higher thermal resistance. On the other hand, the areas with lower thermal resistance are located in regions with higher blood supply and thinner subcutaneous adipose tissue (wrist, temple and hand). The variability, the standard deviation and the distribution of the present results agree with previous studies [19-21].

Wide differences in thermal resistances up to $12 \mathrm{~K} \mathrm{~W}^{-1}$ are observed between subjects when comparing the same anatomical regions. These differences are likely due to between-subjects variation in tissue composition and perfusion.

The phenomena of vasoconstriction and vasodilation are part of the body temperature regulation mechanisms. The higher the blow flow, the greatest the energy transferred from the skin to the environment. This implies a higher thermal conductivity (lower thermal resistance). For this reason, a relationship between heat flow and thermal resistance is expected. In fact, clear correlation between equivalent thermal resistance and heat flow was observed (Fig. 8).

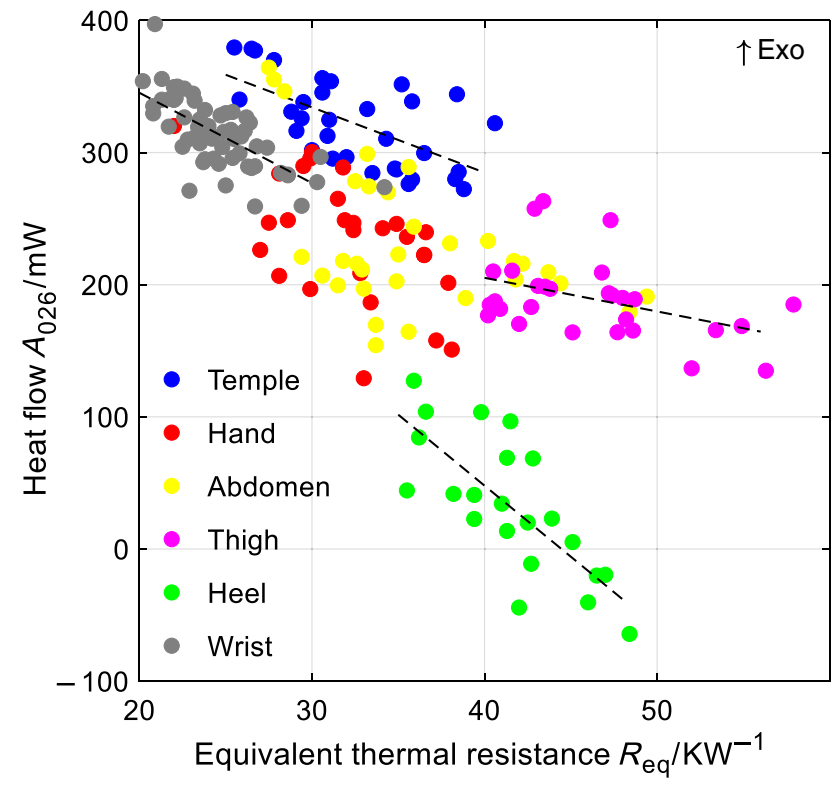

Fig. 8 Correlation between the equivalent thermal resistance and the heat flow for the thermostat temperature of $26{ }^{\circ} \mathrm{C}$, for each surface of the human body (temple, hand, abdomen, thigh, wrist and heel). Regression lines for thigh, heel, wrist and temple are shown. Table 7 shows the fit coefficients

Table 7 shows the parameters of each adjustment made. There are large differences between zones. The peripheral zones (wrist, hand and heel) present a higher slope $(-6.74$ $\left.\times 10^{-3},-6.83 \times 10^{-3},-10.7 \times 10^{-3}\right)$ than the more central zones $\left(-2.55 \times 10^{-3},-4.73 \times 10^{-3}, 4.93 \times 10^{-3}\right)$.

\section{General observations}

In this work, no significant correlations were observed between the thermal results and the heart rate or blood pressure. There are also no significant correlations between thermal results and relative humidity. Correlations between human body heat exchange and heart rate, blood pressure or relative humidity have been reported in several studies

Table 7 Parameters of the linear adjustment between heat flow with thermostat at $26{ }^{\circ} \mathrm{C}\left(A_{026}\right)$ and the equivalent thermal resistance for each zone

\begin{tabular}{lllll}
\hline Zone & $a / \mathrm{W}$ & $b / \mathrm{W}^{2} \mathrm{~K}^{-1}$ & Pearson coef. & $p$ value \\
\hline Temple & 0.482 & $-4.93 \times 10^{-3}$ & -0.63 & $1.2 \times 10^{-4}$ \\
Hand & 0.452 & $-6.74 \times 10^{-3}$ & -0.57 & $2.1 \times 10^{-4}$ \\
Abdomen & 0.401 & $-4.73 \times 10^{-3}$ & -0.50 & $4.1 \times 10^{-3}$ \\
Thigh & 0.307 & $-2.55 \times 10^{-3}$ & -0.42 & $2.5 \times 10^{-3}$ \\
Heel & 0.478 & $-10.7 \times 10^{-3}$ & -0.76 & $5.0 \times 10^{-5}$ \\
Wrist & 0.482 & $-6.83 \times 10^{-3}$ & -0.70 & $6.7 \times 10^{-9}$ \\
Model adjusted: $A_{026}=a+b \cdot R_{\text {eq }}\left(A_{026}\right.$ in $W, R_{\text {eq }}$ in $\left.\mathrm{KW}^{-1}\right)$ \\
\hline
\end{tabular}

Mean RMSE value is $33 \mathrm{~mW}$ 
Fig. 9 Measurement areas A and $\mathrm{B}$ and temporal evolution of the lesion under study
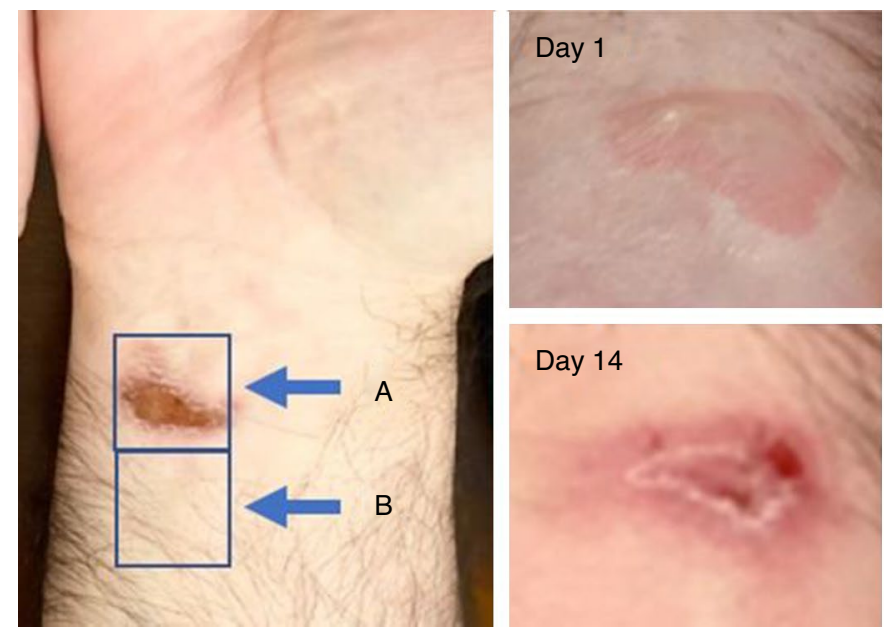

$[35,36]$. However, our measurements were taken with the subjects resting peacefully in controlled environmental conditions, and therefore, no great variation in heat flow was expected due to changes in heat production of blood flow distribution during the measurements. It would be interesting to determine how much can these variables change with exercise and other experimental situations affecting environmental conditions and cutaneous blood flow to define the range of physiological variation for each region in humans.

\section{Temporal thermal study of a second-degree burn on the wrist}

This section presents a temporal thermal study of a minor superficial partial thickness (second-degree) burn injury of $2 \times 1 \mathrm{~cm}^{2}$ in the volar area of the right wrist of subject 1 . The burn was the result of a domestic accident when ironing clothes. The day after the accident, measurements were taken in that area (A in Fig. 9), and from the 5th day, measurements were also taken in a nearby area (B in Fig. 9). Images of the lesion on different days are also shown in Fig. 9. These measurements allow to study the variation of the thermal properties of burned skin measured over time (35 days). Figure 10 shows the temporal evolution of the thermal properties in the injured and non-injured area of the right wrist (areas A and B of Fig. 9).

The most characteristic change of thermal parameters of this injured area is the decrease in heat capacity. The normal value is $5.8 \mathrm{~J} \mathrm{~K}^{-1}$ and in the first week it dropped to $4.2 \mathrm{~J} \mathrm{~K}^{-1}, 27.6 \%$. This heat capacity decrease agrees with DSC measurements done by Wiegand et al. [14]. On day 20 , there was some bleeding from the wound, coinciding with a second decrease in heat capacity, which progressively returned to its healthy state value. As depicted in Fig. 6, the values of heat capacity of the injured area in the first week are well below the values of heat capacity of the neighbouring area.

In the first week, there was also a decrease in the equivalent thermal resistance from 27.7 to $24.4 \mathrm{~K} \mathrm{~W}^{-1}, 11.6 \%$. As we have already indicated in the previous section, a decrease in thermal resistance produces an increase in heat flow, and this is clearly observed in parameter $A_{026}$ that was increased by $62 \mathrm{~mW}(+22.5 \%)$. A slight increase in $A_{036}$ was also observed. The values of equivalent thermal resistance of the injured area during the first week are shown in Fig. 7. Most of the thermal resistance values of the injured area were below those of the healthy area.

It is interesting to indicate that the transitory contact energy $\left(A_{1} \tau_{1}\right)$ of the injured area of the wrist (zone $\mathrm{A}$ in Fig. 9) was lower than that obtained in the healthy zone (zone B in Fig. 9). The measurements in the lesion were $59.4 \%$ lower than in the healthy area (hollow points in Fig. 5b). In the injured area, the mean value of $A_{1}$ was $1.56 \mathrm{~W}$ during the first week, compared to $2.49 \mathrm{~W}$ in the healthy. On the other hand, the time constants $\tau_{1}$ are similar in both cases. A possible cause of this phenomenon is that as the heat capacity decreases, the energy required to achieve a thermal equilibrium is lower. Twenty-five days later, all the thermal parameters reached a steady state at values close to those of the healthy neighbouring area after 25 days.

\section{Conclusions}

A calorimetric sensor has been used to measure in vivo the heat flow of the human body cutaneous surface in 6 zones of 6 subjects at rest, for two different temperatures of the sensor thermostat $\left(26\right.$ and $\left.36{ }^{\circ} \mathrm{C}\right)$. The heat capacity and thermal resistance have been determined. 

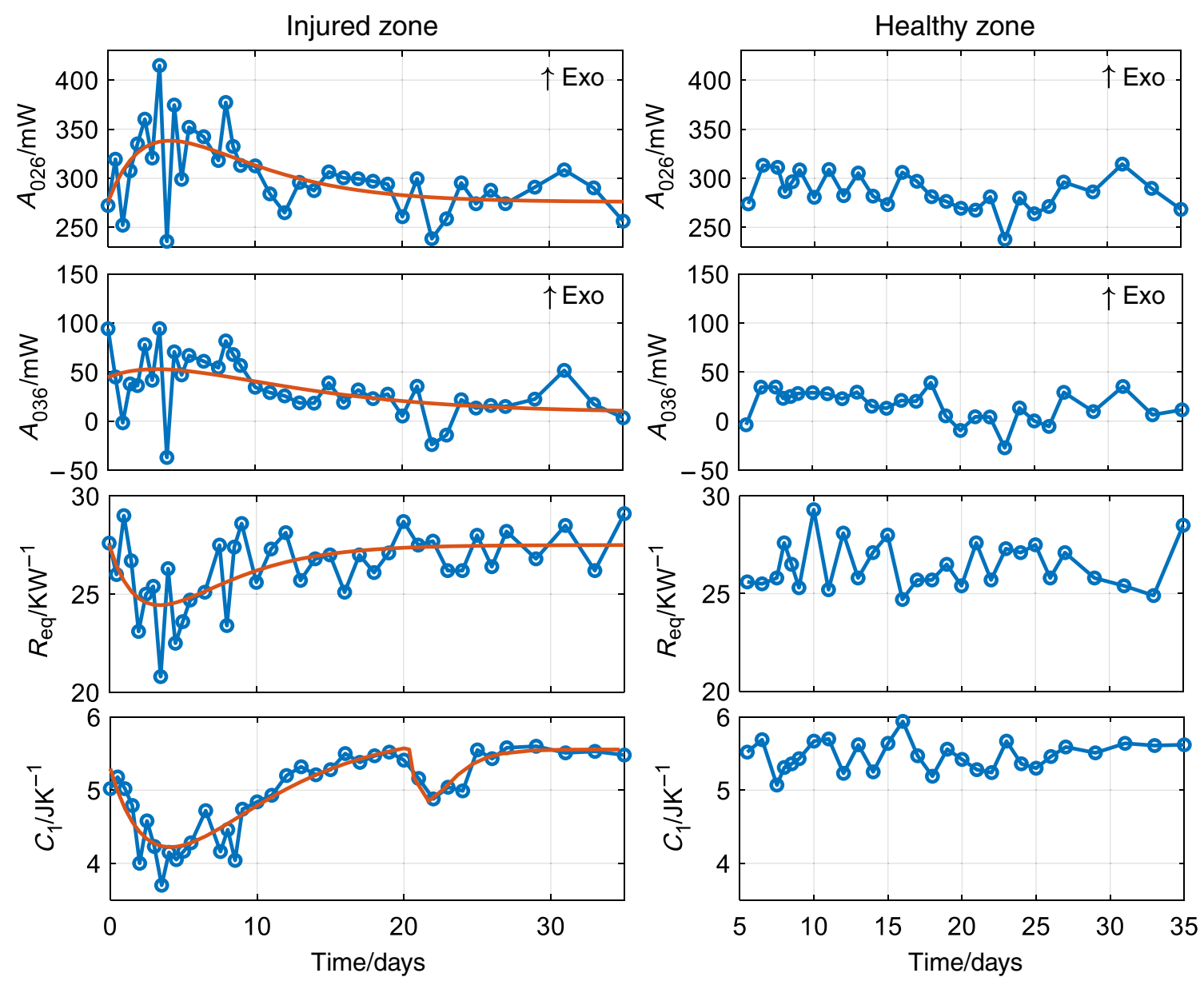

Fig. 10 Temporal evolution of the flow of heat $A_{026}$ and $A_{036}$, of the equivalent thermal resistance $R_{\text {eq }}$ and of the heat capacity $C_{1}$ in the injured and healthy areas of the right wrist (areas A and B of Fig. 9)

The heat flow in resting conditions varies depending on the zone, from 36 to $362 \mathrm{~mW}$ for the sensor thermostat at $26{ }^{\circ} \mathrm{C}$. This magnitude is proportional to the difference in temperature between the skin and the environment and its value is different in each area. The heat flow is higher in central than peripheral regions, likely due to differences in tisular perfusion as indirectly indicated by the higher skin temperature of the central areas. There were also differences related to age. For the population considered, older subjects dissipate more energy than younger subjects; in the heel and the hand but not in the other zones. The equivalent thermal resistance at rest ranges from 20 to $58 \mathrm{KW}^{-1}$. It is different in each area and depends on the physiological state of the subject. It is higher in areas prone to fat accumulation and lower in peripheral areas or close to the bloodstream. This magnitude is inversely proportional to the heat flow. The proportionality factor has been evaluated and is different in each area. The heat capacity at rest varies little, and each area has a different value, which depends mainly on the anatomy of the region studied. The lowest heat capacities are detected in the hand, the heel and the temple, and the largest in the abdomen and wrist.

Measurements taken on a $2 \times 1 \mathrm{~cm}^{2}$ second-degree burn on the wrist of one of the subjects have been presented. Heat capacity is reduced during the first week after injury and then stabilizes back to its normal value. The equivalent thermal resistance decreases, producing an increase in the heat flow, and the transient contact energy presents lower values.

Author contributions Fabiola Socorro, Manuel Rodríguez de Rivera and Pedro Jesús Rodríguez de Rivera had contributed equally to the investigation. Miriam Rodríguez de Rivera and Jose A.L. Calbet had contributed to the medical methodology of the work. Gustavo Marrero Callicó had contributed to the validation and supervision of the research. All authors have read and agreed to the published version of the manuscript.

Funding Open Access funding provided thanks to the CRUE-CSIC agreement with Springer Nature. This work research was funded by the "Ministerio de Ciencia, Innovación y Universidades" (Spain), Grant Number FPU18/02990. Grant holder: Pedro Jesús Rodríguez de Rivera. 
Open Access This article is licensed under a Creative Commons Attribution 4.0 International License, which permits use, sharing, adaptation, distribution and reproduction in any medium or format, as long as you give appropriate credit to the original author(s) and the source, provide a link to the Creative Commons licence, and indicate if changes were made. The images or other third party material in this article are included in the article's Creative Commons licence, unless indicated otherwise in a credit line to the material. If material is not included in the article's Creative Commons licence and your intended use is not permitted by statutory regulation or exceeds the permitted use, you will need to obtain permission directly from the copyright holder. To view a copy of this licence, visit http://creativecommons.org/licenses/by/4.0/.

\section{References}

1. Demongeot J, Flet-Berliac Y, Seligmann H. Temperature decreases spread parameters of the new covid-19 case dynamics. Biology. 2020;9(5):94.

2. Rokita E, Rok T, Taton G. Application of thermography for the assessment of allergen-induced skin reactions. Med Phys. 2011;38:765-72

3. Vecchio PC, Adebajo AO, Chard MD, Thomas PP, Hazleman BL. Thermography of frozen shoulder and rotator cuff tendinitis. Clin Rheumatol. 1992;11(3):382-4.

4. Rajapakse C, Grennan DM, Jones C, Wilkinson L, Jayson M. Thermography in the assessment of peripheral joint inflammation-a re-evaluation. Rheumatol Rehabil. 1981;20(2):81-7.

5. Godoy SE, Hayat MM, Ramirez DA, Myers SA, Padilla RS, Krishna S. Detection theory for accurate and non-invasive skin cancer diagnosis using dynamic thermal imaging. Biomed Opt Express. 2017;8(4):2301-23.

6. Brooks AG, Withers RT, Gore CJ, Vogler AJ, Plummer J, Cormack J. Measurement and prediction of METs during household activities in 35- to 45-year-old females. Eur J Appl Physiol. 2004;91(5-6):638-48.

7. Alves VGF, da Rocha EEM, Gonzalez MC, Fonseca RBV, Silva MHD. Resting energy expenditure measured by indirect calorimetry in obese patients: variation within different BMI ranges. $\mathrm{J}$ Parenter Enterp Nutr. 2020;44(1):129-37.

8. Nakagata T, Yamada Y, Naito H. Metabolic equivalents of body weight resistance exercise with slow movement in older adults using indirect calorimetry. Appl Physiol Nutr Metab. 2019;44(11):1254-7.

9. Speakman JR, Selman C. Physical activity and resting metabolic rate. Proc Nutr Soc. 2003;62(3):621-34.

10. Castellani JW, Young AJ, Kain JE, Sawka MN. Thermoregulatory responses to cold water at different times of day. J Appl Physiol. 1999;87(1):243-6.

11. Pandolf KB, Gange RW, Latzka WA, Blank IH, Young AJ, Sawka MN. Human thermoregulatory responses during cold water immersion after artificially induced sunburn. Am J Physiol. 1992;262(4):R617-23.

12. Brauer A, English MJM, Sander H, Timmermann A, Braun U, Weyland W. Construction and evaluation of a manikin for perioperative heat exchange. A Anaesthesiol Scand. 2002;46(1):43-50.

13. Codau TC, Onofrei E, Bedek G, Dupont D, Cochrane C. Embedded textile heat flow sensor characterization and application. Sens Actuat A Phys. 2015;235:131-9.

14. Wiegand N, Naumov I, Nőt LG, Vámhidy L, Lőrinczy D. Differential scanning calorimetric examination of pathologic scar tissues of human skin. J Therm Anal Calorim. 2013;111(3):1897-902.
15. Mehdi M, Fekecs T, Zapf I, Fekecs T, Lőrinczy D. Differential scanning calorimetry (DSC) analysis of human plasma in different psoriasis stages. J Therm Anal Calorim. 2013;111(3):1801-4.

16. Deng ZS, Liu J. Blood perfusion-based model for characterizing the temperature fluctuation in living tissues. Phys A. 2001;300(3-4):521-30.

17. Hassanpour S, Saboonchi A. Modeling of heat transfer in a vascular tissue-like medium during an interstitial hyperthermia process. J Therm Biol. 2016;62:150-8.

18. Agrawal M, Pardasani KR. Finite element model to study temperature distribution in skin and deep tissues of human limbs. J Therm Biol. 2016;62:98-105.

19. Kharalkar NM, Hayes LJ, Valvano JW. Pulse-power integrateddecay technique for the measurement of thermal conductivity. Meas Sci Technol. 2008;19(7):075104.

20. Okabe T, Fujimura T, Okajima J, Aiba S, Maruyama S. Noninvasive measurement of effective thermal conductivity of human skin with a guard-heated thermistor probe. Int J Heat Mass Transf. 2018;126:625-35.

21. Webb RC, Pielak RM, Bastien P, Ayers J, Niittynen J, Kurniawan $\mathrm{J}$, et al. Thermal transport characteristics of human skin measured in vivo using ultrathin conformal arrays of thermal sensors and actuators. PloS ONE. 2015;10(2):e018131.

22. Marchiori B, Regal S, Arango Y, Delattre R, Blayac S, Ramuz M. PVDF-TrFE-based stretchable contact and non-contact temperature sensor for e-skin application. Sensors. 2020;20(3):623.

23. Gao L, Zhang Y, Malyarchuk V, Jia L, Jang KI, Webb RC, Fu H, Shi Y, Zhou G, Shi L, et al. Epidermal photonic devices for quantitative imaging of temperature and thermal transport characteristics of the skin. Nat Commun. 2014;4:4938.

24. Tian L, Li Y, Webb RC, Krishnan S, Bian Z, Song J, Ning X, Crawford K, Kurniawan J, Bonifas A, et al. Flexible and stretchable 3 omega sensors for thermal characterization of human skin. Adv Funct Mater. 2017;27(26):1701282.

25. Socorro F, Rodríguez de Rivera PJ, Rodríguez de Rivera M. Calorimetric minisensor for the localized measurement of surface heat dissipated from the human body. Sensors. 2016;16(11):1864.

26. Rodríguez de Rivera PJ, Rodríguez de Rivera M, Socorro F, Rodríguez de Rivera $\mathrm{M}$. Measurement of human body surface heat flux using a calorimetric sensor. J Therm Biol. 2019;81:178-84.

27. Rodríguez de Rivera PJ, Rodríguez de Rivera M, Socorro F, Rodríguez de Rivera M, Callicó GM. A method to determine human skin heat capacity using a non-invasive calorimetric sensor. Sensors. 2020;20(12):3431.

28. Kirchner R, Rodríguez de Rivera M, Seidel J, Torra V. Identification of micro-scale calorimetric devices-Part VI. An approach by RC-representative model to improvements in TAM microcalorimeters. J Therm Anal Calc. 2005;82(1):179-84.

29. Cain JB, Livingstone SD, Nolan RW, Keefe AA. Respiratory heat loss during work at various ambient temperatures. Respir Physiol. 1990;79(2):145-50.

30. Kurazumil Y, Rezgals L, Melikov AK. Convective heat transfer coefficients of the human body under forced convection from ceiling. J Ergonomics. 2014;4:126.

31. Taylor NAS, Tipton MJ, Kenny GP. Considerations for the measurement of core, skin and mean body temperatures. J Therm Biol. 2014;46:72-101.

32. Havenith G. Human surface to mass ratio and body core temperature in exercise heat stress-a concept revisited. J Therm Biol. 2001;26(4-5):387-93.

33. Iyoho A, $\mathrm{Ng} \mathrm{L}, \mathrm{McFadden} \mathrm{L.} \mathrm{Modelling} \mathrm{of} \mathrm{gender} \mathrm{differences} \mathrm{in}$ thermoregulation. Milit Med. 2017;182:295-303.

34. https://itis.swiss/virtual-population/tissue-properties/database/ thermal-conductivity/. Accessed 14 June 2020. 
35. Buller MJ, Tharion WJ, Cheuvront SN, et al. Estimation of human core temperature from sequential heart rate observations. Physiol Meas. 2013;34(7):781-98.

36. Welles AP, Xu X, Santee WR, et al. Estimation of core body temperature from skin temperature, heat flux, and heart rate using a Kalman filter. Comput Biol Med. 2018;99:1-6.
Publisher's Note Springer Nature remains neutral with regard to jurisdictional claims in published maps and institutional affiliations. 